Original Research Paper

\title{
Struktur Komunitas Karang Keras (Scleractinia) di Zona Intertidal Pantai Mandalika Lombok Tengah
}

\author{
Siti Nurhaliza', Muhlis ${ }^{2 *}$, Imam Bachtiar ${ }^{3}$, Didik Santoso $^{4}$ \\ 1,2,3,4 Program Studi Pendidikan Biologi PMIPA FKIP, Universitas Mataram, Mataram, Indonesia.
}

\section{Riwayat artikel}

Received: 8 Oktober 2019

Revised: 22 Oktober 2019

Accepted: 19 November 2019

Published: 30 Desember 2019

*Corresponding Author:

Muhlis,

Program Studi Pendidikan

Biologi PMIPA FKIP

Universitas Mataram,

Mataram, Indonesia

Email:

muhlis.ocean@unram.ac.id
Abstrak: Zona intertidal merupakan daerah pantai yang terletak antara pasang tertinggi dan surut terendah. Salah satu ekosistem yang terdapat di kawasan intertidal adalah ekosistem terumbu karang. Terumbu karang merupakan salah satu ekosistem laut yang menjadi sumber kehidupan bagi berbagai biota laut sehingga keberadaannya sangat penting, baik dari segi ekologis maupun ekonomis. Pantai Mandalika memiliki ekosistem terumbu karang dengan zona intertidal yang cukup luas. Pesatnya perkembangan wisata di Pantai Mandalika secara tidak langsung akan mempengaruhi kehidupan terumbu karang. Penelitian ini dilakukan untuk menyediakan data dan informasi terkini mengenai kondisi keanekaragaman karang keras di zona intertidal Pantai Mandalika yang mencakup komposisi spesies, famili dan bentuk pertumbuhan, serta indeks ekologi (indeks keanekaragaman, keseragaman dan dominansi spesies). Pengambilan data dilakukan pada bulan Juni 2019 selama periode surut terendah di kawasan intertidal. Metode yang digunakan yaitu metode Underwater Photo Transect (UPT). Hasil penelitian ini menemukan 30 spesies karang keras yang termasuk dalam 8 famili di zona intertidal Pantai Mandalika. Favites paraflexuosa adalah spesies yang paling banyak ditemukan di daerah tersebut dengan persentase $22 \%$. Famili Faviidae (79\%) memiliki persentase terbesar di semua transek. Ada 5 jenis bentuk pertumbuhan karang keras di daerah yang $87 \%$ di antaranya adalah bentuk karang masif. Nilai indeks keanekaragaman Shannon-Wiener adalah 2,5 dengan indeks keseragaman 0,8, dan indeks dominansi 0,1 .

Kata kunci: komunitas, terumbu karang, zona intertidal, keanekaragaman, Pantai Mandalika.

Abstract: The intertidal zone is a coastal area located between the highest and lowest tides. One of the ecosystems in the intertidal area is the coral reef ecosystem. The coral reef is one of the marine ecosystems which is a source of life for various marine biota so that its existence is very important, both in ecological and economic terms. Mandalika Beach has a coral reef ecosystem with a fairly extensive intertidal zone. The rapid development of tourism in Mandalika Beach will indirectly affect the life of coral reefs. This research to provide data for the existing condition of hard corals diversity in the area for better understanding of future research. This research covers the species, family and life form composition, and ecologycal indices (diversity, species equitability, and dominance indices). The research was conducted on June 2019 during the lowest tide period and carried out with a Underwater Photo Transect (UPT) method. The results revealed that Mandalika's Intertidal Zone had 30 species of hard corals that belongs to 8 families. Favites paraflexuosa was the most abundant coral in the area with $22 \%$ of community composition. The Faviidae family (79\%) had the largest percentage in all transects. There were 5 type life forms of hard corals in the area which $92 \%$ of them were coral massive type. The Shannon-Wiener diversity index score was 2.5 with equitability index 0.8 , and dominance index is 0.1 .

Keywords: community coral reef, intertidal zone, diversity, Mandalika Beach. 


\section{Pendahuluan}

Terumbu karang merupakan salah satu ekosistem laut yang menjadi sumber kehidupan bagi berbagai biota laut sehingga keberadaannya sangat penting, baik dari segi ekologis maupun ekonomis. Fungsi ekologis terumbu karang antara lain, sebagai pencegah terjadinya erosi, sebagai tempat tinggal, mencari makan, berlindung, dan memijah ikan serta biota laut lainnya. Sedangkan dari segi ekonomi, terumbu karang dapat dijadikan sebagai objek wisata yang dapat menjadi sumber pendapatan manusia (Giyanto, 2018). Salah satu pantai dengan zona intertidal yang memiliki ekosistem terumbu karang adalah Pantai Mandalika.

Pantai Mandalika merupakan pantai yang terdapat di selatan Pulau Lombok. Pantai Mandalika terletak di Desa Kuta, Kecamatan Pujut, Kabupaten Lombok Tengah. Kawasan pantai ini merupakan Kawasan Ekonomi Khusus (KEK) yang sedang dikembangkan oleh pemerintah, khususnya pada sektor wisata. Salah satu wisata unggulan di kawasan ini adalah budaya "bau nyale" (menangkap cacing nyale) yang diadakan satu kali setahun. Budaya bau nyale ini merupakan tradisi yang sangat penting bagi masyarakat sasak, sehingga kelestariannya perlu dijaga. Kawasan intertidal Pantai Mandalika sangat penting bagi kelestarian budaya bau nyale, dimana habitat cacing nyale tersebut adalah terumbu karang di daerah antarpasut (intertidal) (Bachtiar et al., 2016).

Pesatnya perkembangan sektor wisata di Pantai Mandalika dikhawatirkan meningkatkan gangguan antropogenik pada kawasan tersebut, yang akan mempengaruhi kehidupan terumbu karang. Salah satu aktivitas yang rutin dilakukan oleh warga di Pantai Mandalika adalah 'madak' yang merupakan kegiatan mencari biota laut yang dapat dikonsumsi atau bernilai ekonomis. Kegiatan madak di Pantai Mandalika seringkali dilakukan dengan penggunaan alat-alat tambahan yang bersifat destruktif.

Kegiatan madak memiliki efek jangka panjang, yaitu dapat merusak terumbu karang di zona intertidal Pantai Mandalika sehingga dapat mengancam kelestarian ikon wisata Pantai Mandalika yaitu budaya bau nyale, sebagaimana terumbu karang merupakan habitat dari cacing nyale tersebut. Akibat dari tekanantekanan tersebut, maka penting untuk diadakannya pengelolaan kawasan agar kegiatan madak dan aktivitas manusia lainnya dapat terkontrol, sehingga kelestariannya dapat terjaga. Dasar untuk mengelola ekosistem terumbu karang memerlukan informasi terkait kondisi terkini mengenai struktur komunitas karang di Pantai Mandalika. Komunitas karang sangat penting diketahui untuk mendeteksi perubahanperubahan yang terjadi pada habitat cacing nyale.

Ketersediaan data dan informasi mengenai struktur komunitas karang (Scleractinia) di zona intertidal Pantai Mandalika belum tersedia, sehingga penelitian ini penting dilakukan. Hasil penelitian ini diharapkan dapat menjadi sumber tambahan informasi dan data dasar mengenai struktur komunitas karang (Scleractinia) di zona intertidal bagi pemerintah untuk lebih meningkatkan upaya pelestarian, khususnya di kawasan intertidal Pantai Mandalika dan menjadi rujukan bagi penelitian di masa mendatang.

\section{Bahan dan Metode}

\section{a. Lokasi Penelitian}

Penelitian ini dilakukan di kawasan intertidal Pantai Mandalika Lombok Tengah pada bulan Juni 2019 selama periode surut terendah. Pantai Mandalika yang terletak di antara Pantai Serinting dan Pantai Seger (Gambar 1).
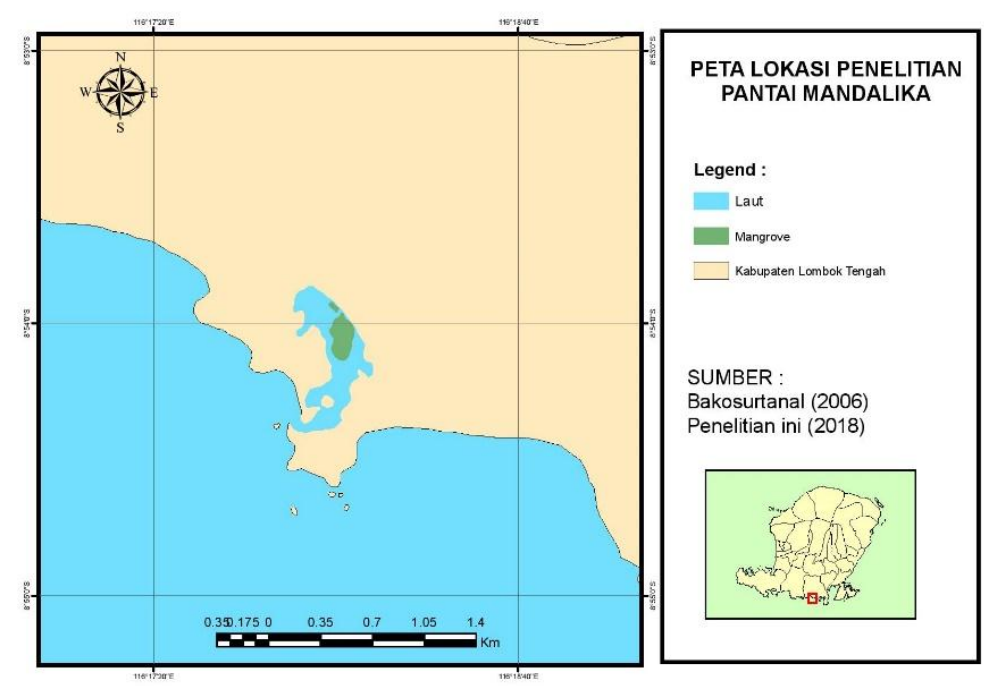

Gambar 1. Peta lokasi penelitian karang keras di zona intertidal Pantai Mandalika.

\section{b. Bahan dan Metode}

Pengambilan data karang dilakukan pada zona intertidal atau reefflat yang disesuaikan dengan kondisi terumbu karang. Pengambilan data karang menggunakan metode Underwater Photo Transect (UPT) dengan panjang transek 80 meter dan ukuran bingkai yang digunakan adalah $58 \mathrm{~cm} \mathrm{x} 44 \mathrm{~cm}$ (Giyanto 
2013). Foto diambil dengan menggunakan waterproof camera. Bingkai diletakkan di sepanjang garis transek secara berselang-seling kiri dan kanan dengan interval satu meter. Dari setiap garis transek diambil sebanyak 80 foto. Spesies dan koloni dalam setiap bingkai diindentifikasi dan dihitung jumlah serta bentuk pertumbuhannya. Identifikasi spesies karang mengacu pada buku Coral Finder Indo Pasific (Kelley, 2009), Coral of The World (Veron, 2000), Coral Australia and Indo-Pasific (Veron, 1986), dan Jenis-Jenis Karang di Indonesia (Suharsono, 2008). Adapun identifikasi bentuk pertumbuhan karang mengacu pada English et al. (1997). Jumlah transek adalah 5 transek dengan jarak masing-masing transek 50-100 meter.

Data hasil pengamatan karang keras yang diperoleh kemudian dianalisis secara kualitatif dan kuantitatif. Analisis data secara kualitatif meliputi analisis secara deskriptif kekayaan spesies, komposisi spesies, komposisi famili, dan komposisi bentuk pertumbuhan karang keras yang ditemukan di zona intertidal Pantai Mandalika. Analisis kuantitatif meliputi, indeks keanekaragaman spesies (H'), indeks keseragaman (J), dan indeks dominansi spesies (C) yang dinyatakan dalam rumus di bawah ini:

$$
\mathrm{H}^{\prime}=-\sum_{i=1}^{S} P i \ln P i ; P i \quad=\frac{\mathrm{ni}}{\mathrm{N}}
$$

Tabel 1. Nama spesies-spesies karang keras yang ditemukan di zona intertidal Pantai Mandalika.

\begin{tabular}{lll}
\hline No & Famili & Spesies \\
\hline 1 & Acroporidae & Acropora humilis \\
2 & Acroporidae & Acropora sp. \\
3 & Acroporidae & Astreopora sp. \\
4 & Acroporidae & Montipora sp. \\
5 & Faviidae & $\begin{array}{l}\text { Cyphastrea } \\
\text { microphthalma }\end{array}$ \\
6 & Faviidae & Cyphastrea sp. \\
7 & Faviidae & Favites abdita \\
8 & Faviidae & F. bestae \\
9 & Faviidae & F. paraflexuosa \\
10 & Faviidae & F. pentagona \\
11 & Faviidae & Favites sp. 1 \\
12 & Faviidae & Favites sp. 2 \\
13 & Faviidae & Favites sp. 3 \\
14 & Faviidae & Favia sp. 1 \\
15 & Faviidae & Favia sp. 2 \\
\hline
\end{tabular}

Kekayaan spesies karang keras di zona intertidal Pantai Mandalika sebanyak 30 spesies yang tergolong dalam 15 genus dan 8 famili. Kekayaan spesies ini berbeda jika dibandingkan dengan penelitian Brown et al. (1983) yang melaporkan bahwa terdapat sebanyak 88 spesies karang dari 28 genus pada zona intertidal perairan Pulau Pari. Hal serupa juga di laporkan Wolstenholme et al. (1997) bahwa terdapat 79 spesies karang di zona intertidal Darwin Region,
Keterangan:

$$
\begin{gathered}
J=\frac{H^{\prime}}{H \max }=\frac{-\sum_{i=1}^{n} P i \ln P i}{\ln S} \\
\mathrm{C}=\sum_{i=1}^{n}\left(n i /{ }_{N}\right)^{2}
\end{gathered}
$$

ni = Jumlah koloni spesies karang ke-i

$\mathrm{N}=$ Jumlah koloni karang total

$\mathrm{S}=$ Jumlah seluruh spesies karang

(Begon et al., 2006; Odum, 1993).

\section{Hasil dan Pembahasan}

\section{a. Kekayaan Spesies}

Terumbu karang yang diamati pada penelitian ini termasuk tipe terumbu karang tepi (fringing reef). Terumbu karang di zona intertidal Pantai Mandalika tersusun atas 30 spesies karang keras (Scleractinia) yang tergolong dalam 15 genus dan 8 famili yaitu Acroporidae (4 spesies), Faviidae (17 spesies), Helioporidae (1 spesies), Meandrinidae (1 spesies), Mussidae (1 spesies), Pocilloporidae (2 spesies), Poritidae (3 spesies), dan Siderastreidae (1 spesies).

\begin{tabular}{|c|c|c|}
\hline No & Famili & Spesies \\
\hline 16 & Faviidae & Favia sp. 3 \\
\hline 17 & Faviidae & Favia sp. 4 \\
\hline 18 & Faviidae & Goniastrea aspera \\
\hline 19 & Faviidae & G. favulus \\
\hline 20 & Faviidae & Goniastrea sp. \\
\hline 21 & Faviidae & Platygyra sp. \\
\hline 22 & Helioporidae & Heliopora coerulea \\
\hline 23 & Meandrinidae & Hydnopora sp. \\
\hline 24 & Mussidae & $\begin{array}{l}\text { Symphyllia } \\
\text { agaricia }\end{array}$ \\
\hline 25 & Pocilloporidae & $\begin{array}{l}\text { Pocillophora } \\
\text { meandrina }\end{array}$ \\
\hline 26 & Pocilloporidae & Pocillophora sp. \\
\hline 27 & Poritidae & Goniopora sp. \\
\hline 28 & Poritidae & Porites solida \\
\hline 29 & Poritidae & Porites sp. \\
\hline 30 & Siderastreidae & Psammocora sp. \\
\hline
\end{tabular}
Kekayaan spesies tersebut diperoleh dari 960 koloni (Tabel 1).
Australia. Selain itu, Latipov (1986) juga melaporkan terdapat 47 spesies karang keras di zona intertidal perairan Pulau Namsu, Laut Cina Selatan. Salah satu penyebab rendahnya kekayaan spesies karang di zona intertidal Pantai Mandalika adalah saat surut terendah di Pantai Mandalika volume air sangat sedikit sehingga banyak karang keras yang terdedah oleh radiasi cahaya matahari. Hal tersebut membatasi jenis karang keras 
yang dapat tumbuh pada zona intertidal Pantai Mandalika.

Penyebab lain sedikitnya spesies karang keras yang ditemukan di zona intertidal Pantai Mandalika adalah akivitas masyarakat menangkap ikan atau biota bernilai ekonomis penting atau dalam bahasa lokal kegiatan ini disebut madak. Kegiatan madak ini menggunakan alat yang tidak ramah lingkungan seperti tuba atau potas (racun alamiah untuk menangkap ikan), linggis, gancu, sabit, gareng, dan alat bersifat dekstruktif lainnya (Bachtiar et al., 2016). Hal tersebut dikhawatirkan dapat mengganggu atau bahkan merusak karang keras di zona intertidal.

Kerusakan lain disebabkan oleh kegiatan wisata bau nyale yang rutin diadakan setiap tahun yang dihadiri oleh puluhan ribu wisatawan dan masyarakat lokal. Pada acara bau nyale tahun 2016, dengan metode sensus tercatat sekitar 27.000 orang berada di pantai (Bachtiar et al., 2016). Kegiatan ini mencari cacing nyale, dimana kegiatan tersebut juga menginjak-injak karang, sehingga dikhawatirkan dapat merusak karang intertidal Pantai Mandalika serta mengancam wisata bau nyale itu sendiri, dimana habitat cacing nyale adalah terumbu karang intertidal (Bachtiar et al., 2016).

\section{b. Komposisi Spesies}

Komposisi spesies dengan proporsi tertinggi di zona intertidal Pantai Mandalika adalah spesies karang masif yaitu $F$. paraflexuosa, Goniastrea sp. dan $G$. favulus dengan persentase secara berturut-turut yaitu $22 \%, 12 \%$, dan $11 \%$ (Gambar 2). Hal serupa dilaporkan Luthfi (2003), bahwa karang masif seperti seperti $F$. abdita, Favia speciosa, dan Porites lobata juga paling banyak ditemukan di daerah intertidal (reef flat) Pulau Panjang. Demikian juga dengan Babcock (1986) melaporkan bahwa karang masif yaitu G. favulus, G. aspera, dan Platygyra sinensis memiliki kepadatan yang paling tinggi di daerah intertidal Magnetic Island, Queensland. Hal ini diduga karang tersebut memiliki mekanisme ketahanan diri pada kondisi lingkungan yang ekstrim. Veron (2000) menyatakan bahwa karang jenis $G$. aspera mempunyai mekanisme untuk menyimpan air di dalam kerangkanya untuk menghindari kekeringan akibat terdedah udara bebas dan sinar matahari.

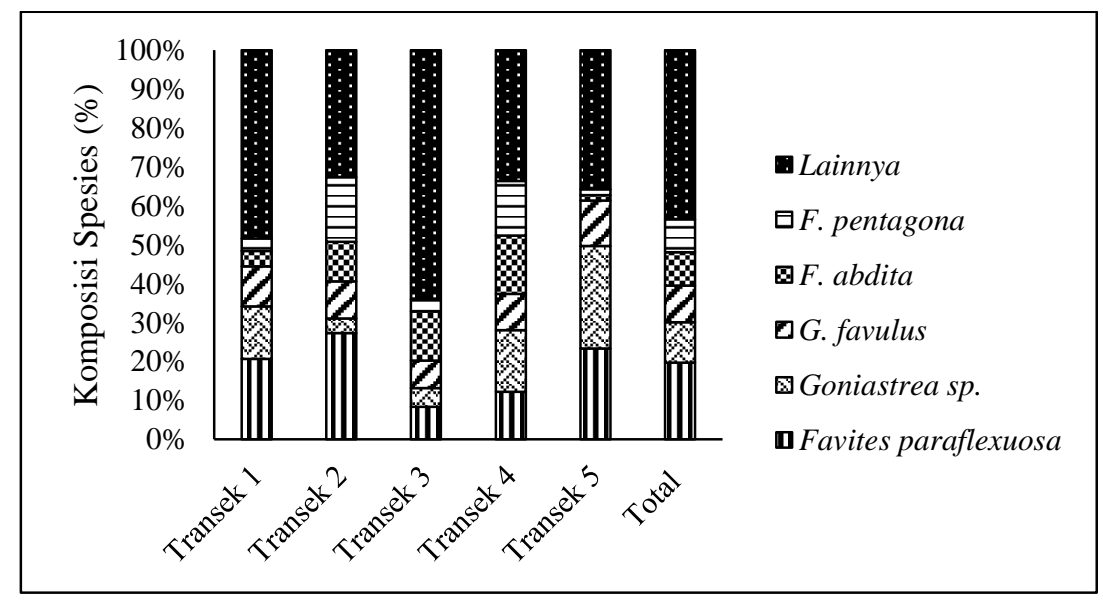

Gambar 2. Perbandingan Komposisi Lima Spesies Karang Keras Paling Dominan di Setiap Transek Pada Zona Intertidal Pantai Mandalika.

Zona intertidal Pantai Mandalika memiliki 8 famili karang yaitu Acroporidae, Faviidae, Helioporidae, Meandrinidae, Mussidae, Pocilloporidae, Poritidae, dan Sideratreidae. Famili Faviidae merupakan famili dengan jumlah total proporsi tertinggi yaitu $79 \%$, kemudian disusul oleh famili Poritidae $13 \%$, dan Acroporidae 4\%. Adapun famili dengan jumlah total proporsi terendah adalah Meandrinidae dan Helioporidae dengan komposisi kurang dari $1 \%$ (Gambar 3). Keberadaan jenis karang keras yang berasal dari famili Faviidae di daerah intertidal atau reef flat memang sudah umum terjadi, dikarenakan jenis karang dari Faviidae ini mempunyai mekanisme ketahanan diri pada kondisi lingkungan yang ekstrim seperti terdedah udara hingga beberapa jam (Veron, 2000; Tianran et al., 2009).

\section{c. Komposisi Famili dan Bentuk Pertumbuhan}

Karang memiliki berbagai macam bentuk pertumbuhan. Pada zona intertidal Pantai Mandalika terdapat 5 macam bentuk pertumbuhan karang yaitu karang acropora digitate/menjari (ACD), karang masif (CM), karang submasif (CS), karang encrusting/mengerak (CE), dan karang Heliopora (CHL) (Gambar 4). Komposisi bentuk pertumbuhan tertinggi di seluruh transek yaitu bentuk massif (CM) $92 \%$. Adapun bentuk pertumbuhan karang terendah yaitu bentuk CHL dengan persentase kurang dari $1 \%$ (Tabel 2). Penemuan ini lebih sedikit dibandingkan dengan penelitian oleh Muhlis (2011) di zona windward dengan kedalaman 3 meter di Gili Trawangan, ditemukan 13 jenis bentuk pertumbuhan, sedangkan di zona leeward dengan kedalaman 10 meter ditemukan 11 
jenis bentuk pertumbuhan karang. Hal tersebut disebabkan karena adanya perbedaan kedalaman dan kondisi lokasi penelitian di Gili Trawangan dengan di zona intertidal Pantai Mandalika.

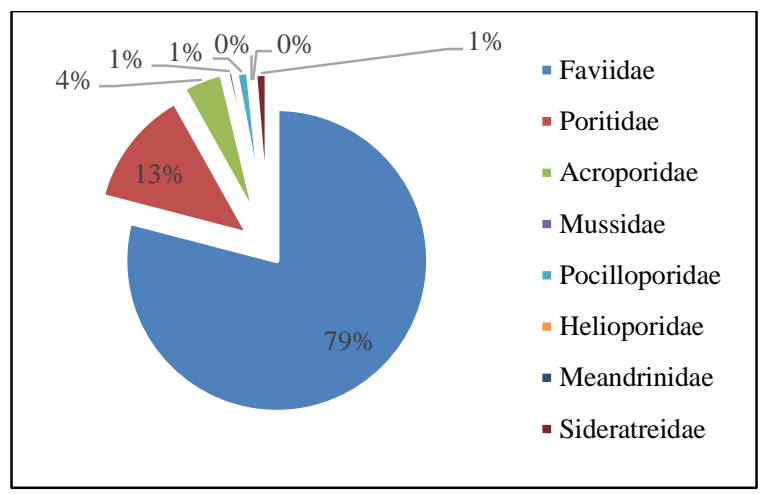

Gambar 3. Komposisi Famili Karang Keras di Zona Intertidal Pantai Mandalika.

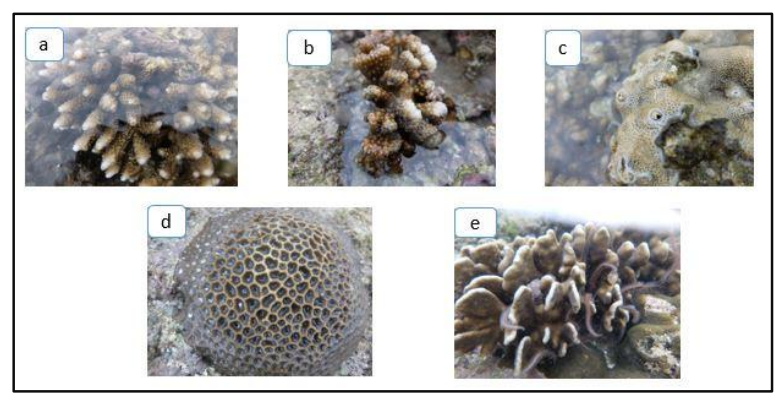

Gambar 4. Bentuk pertumbuhan karang di zona intertidal Pantai Mandalika, a) karang acropora digitate/menjari (ACD), b) karang submasif (CS), c) karang encrusting/mengerak (CE), d) karang masif (CM), dan e) karang Heliopora (CHL) (Dokumentasi Pribadi).

Pada daerah intertidal atau reef flat, bentuk pertumbuhan karang sangat dipengaruhi oleh subaerial exposure, yaitu bila air surut sekali banyak terumbu karang yang muncul di permukaan air. Tanda spesifik subaerial exposure adalah karang yang berbentuk mikro atol (Atmadja, 1999). Mikro atol di hasilkan oleh lebih setengah lusin genus karang dengan berbagai bentuk pertumbuhan yang menciptakan suatu ekosistem yang kaya dan habitat yang bervariasi dari terumbu karang (Suprapto, 2002).

Secara umum karang yang berada di zona intertidal Pantai Mandalika ini adalah bentuk karang masif seperti $F$. paraflexuosa, $F$. abdita, dan Goniastrea $s p$ (Gambar 5). Banyaknya bentuk karang masif dari famili Faviidae di daerah intertidal yang mempunyai kondisi ekstrim disebabkan karena morfologi karang berbentuk masif atau pejal merupakan cara yang efektif bagi biota karang untuk mempertahankan diri dari fragmentasi akibat energi gelombang yang besar. Ada keterkaitan yang sangat kuat antara bentuk pertumbuhan karang dengan energi gelombang di suatu perairan (Luthfi, 2009). Selain itu karang dari jenis Faviidae juga mempunyai kemampuan menyimpan air pada kolumelanya pada saat surut terendah, sehingga jenis karang ini akan terhindar dari kematian akibat terekspos udara dan terdedah sinar matahari secara langsung.

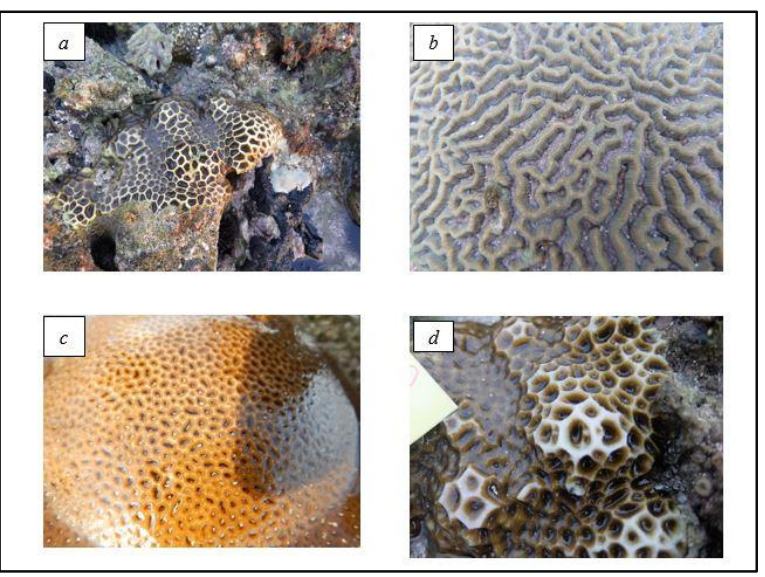

Gambar 4. Jenis-jenis karang yang dominan di zona intertidal Pantai Mandalika, a) $F$. paraflexuosa, b) $G$. favulus, c) Goniastrea sp., d) F. abdita (Dokumentasi Pribadi).

Karang masif mampu beradaptasi dengan kondisi ekstrim seperti tekanan arus yang tinggi, dan perubahan suhu ekstrim (Dollar, 1982; Tianran et al., 2009; Hanapiah, 2019). Dollar (1982) melaporkan bahwa karang masif Porites lobata dan P. compressa memiliki kepadatan yang paling tinggi di perairan Pulau Hawaii dan mampu beradaptasi dengan kondisi tekanan gelombang dan arus tinggi. Hasil survei selama dua tahun oleh Tianran et al. (2009) melaporkan bahwa $F$. abdita merupakan spesies yang paling dominan ditemukan di Daya Bay Laut Cina Selatan dengan kondisi suhu dingin yang ekstrim pada tahun 2008. Hanapiah et al. (2019) juga melaporkan bahwa di Balok, Pahang, Malaysia tutupan karang tertinggi berasal dari Porites, yaitu genus karang masif yang mampu beradaptasi dengan tekanan suhu dan sedimentasi.

Nilai indeks keanekaragaman spesies karang keras di zona intertidal Pantai Mandalika adalah 2,5 dengan nilai indeks keseragaman $(\mathrm{J})$ adalah 0,7 dan nilai indeks dominansi (C) adalah 0,1. Tinggi rendahnya indeks keanekaragaman suatu komunitas dipengaruhi oleh kekayaan spesies dan keseragaman distribusi individu penyusun komunitas tersebut. Semakin tinggi kekayaan spesies dan keseragaman distribusinya, maka semakin tinggi indeks keanekaragamannya dan begitupula sebaliknya. 
Tabel 2. Komposisi bentuk pertumbuhan karang pada zona intertidal Pantai Mandalika.

\begin{tabular}{clccc}
\hline No & Bentuk pertumbuhan & Kode & Jumlah Koloni & Komposisi (\%) \\
\hline 1 & Acropora Menjari & ACD & 9 & 1 \\
2 & Karang Submasif & CS & 31 & 3 \\
3 & Karang Mengerak & CE & 32 & 3 \\
4 & Karang Masif & CM & 886 & 92 \\
5 & Karang Heliopora & CHL & 2 & 0 \\
\hline Total & & 960 & \\
\hline
\end{tabular}

\section{Kesimpulan}

Kekayaan spesies karang yang ditemukan di zona intertidal Pantai Mandalika adalah sebanyak 30 spesies yang tergolong ke dalam 8 famili Komposisi spesies karang tertinggi adalah Favites paraflexuosa, Goniastrea $s p$. dan G. favulus dengan proporsi secara berturut-turut yaitu $22 \%, 12 \%$, dan $11 \%$. Komposisi famili karang tertinggi adalah Faviidae (79\%), Poritidae (13\%), dan Acroporidae (4\%). Komposisi bentuk pertumbuhan karang di zona intertidal Pantai Mandalika yaitu karang masif (92\%), karang encrusting (3\%), karang submasif (3\%), karang acropora digitate (1\%), dan karang Heliopora $(0,2 \%)$. Nilai indeks keanekaragaman spesies, keseragaman, dan dominansi spesies karang keras di Pantai Mandalika berturut-turut adalah 2.5, 0.8 dan 0.1.

\section{Ucapan Terima Kasih}

Terima kasih penulis haturkan kepada semua pihak yang terlibat dalam penelitian ini. Terutama teman-teman yang telah membantu dalam proses pengambilan data, yaitu Cahya Himawan, Fahmi Zuhdi, dan Lale Wahyunnisya.

\section{Daftar Pustaka}

Atmadja, W. S. (1999). Sebaran dan beberapa aspek vegetasi rumput laut (algae makro) di perairan terumbu karang Indonesia. Jakarta: Puslitbang Oseanologi-LIPI.

Babcock, R. C. (1986). A Comparation of the Population Ecology of Reef Flat Corals of the Family Faviidae (Goniastrea, Platygyra). PhD thesis. Townsville: James Cook University.

Bachtiar, I., Karnan, I.I.A Hakim., L. Japa, E. Pradjoko \& Syafruddin (2016). Kajian potensi dampak pembangunan danau di distrik the Lagoon terhadap komunitas cacing nyale di Mandalika
Resort: pengelolaan cacing nyale. Laporan Akhir. Lembaga Penelitian Universitas Mataram.

Begon, M., C.R. Townsend \& J.L. Harper. (2006). Ecology; from Individuals to Ecosystems 4th Edition. Malden: Blackwell Publishing.

Brown, B. E., Holley, M. C., Sya'rani, L. \& Tissier, L. M. (1983). Coral asseblages of reef flats around Pulau Pari, Thousand Islands, Indonesia. Atoll Research Bulletin, 281: 1-13.

Dollar, S. J. (1982). Wave stress and coral community structure in Hawaii. Coral Reefs, 1: 71-81.

English, S, Wilkinson, C. \& Baker, V. (1997). Survey Manual for Tropical Marine Resources $2^{\text {nd }}$ Edition. Townsville: Australia Marine Science Project Living Coastal Resource.

Giyanto (2013). Metode transek foto bawah air untuk penilaian kondisi terumbu karang. Oseanologi dan Limnologi di Indonesia, 38 (1): 47-61.

Giyanto, G., Prayudha, B. \& Hafizt, M. (2018). Status Terumbu Karang Indonesia 2018. Jakarta: LIPI.

Hanapiah, F. M., Saad, S., Ahmad, Z., Yusof, H. M. \& Khodzori, F. A. (2019). Assesment of benthic and coral community structure in an inshore reef in Balok, Pahang, Malaysia. Biodiversitas, 20 (3): 872-877.

Luthfi, M. O. (2003). Sebaran Spasial Karang Keras (Scleractinia) di Perairan Pulau Panjang, Jepara. Skripsi. Jurusan Ilmu Kelautan. Fakultas Perikanan dan Ilmu Kelautan, Universitas Diponegoro. Semarang.

Luthfi, M. O. (2009). Bentuk Pertumbuhan Karang di Wilayah Rataan Terumbu (Reef Flat) Perairan 
Kondang Merak, Malang, Sebagai Strategi Adaptasi Terhadap Lingkungan. Prosiding Pertemuan Ilmiah Tahunan VI ISOI 2009: 109 117.

Muhlis (2011). Ekosistem terumbu karang dan kondisi oseanografi perairan Kawasan Wisata Bahari Lombok. Berkala Penelitian Hayati (Jounal of Biological Researches), 16 (2): 111-118.

Odum, E. P. (1993). Dasar-dasar Ekologi. Jakarta: PT. Gramedia. (Terjemahan).

Kelley, R. (2009). Coral Finder Indo Pasific. Townsville: BYO Guides.

Suharsono (2008). Jenis-jenis Karang di Indonesia. Jakarta: Program COREMAP II-LIPI.

Suprapto (2002). Struktur Komunitas Karang Hermatipik pada Mikro-Atol Dataran Terumbu Pulau Panjang, Jepara. Skripsi. Jurusan Ilmu Kelautan UNDIP. Semarang.
Tianran, C., Kefu, Y. U., Qi, S. H. I., Shu, L. I., Price, G. J., Rong, W., Meixia, Z., Tegu, C... Jianxin, Z. (2009). Twenty-five years of change in scleractinian coral communities of Daya Bay ( northern South China Sea ) and its response to the 2008 AD extreme cold climate event. Chinese Science Bulletin, 54: 2107-2117.

Veron, J.E.N. (1986). Corals of Australia and the IndoPacific. Honolulu: Universitas Hawai Press.

Veron, J.E.N. (2000). Corals of the World. Australian Institute of Marine Science. Townsville: Australia.

Wolstenholme, J., Dinesen, D. Z. \& Alderslade, P. (1997). Hard corals of the Darwin Region, Northern Territory, Australia. Proceedings of the Sixth International Marine Biological Workshop, 381298. 